Older adults' exercise imagery 1

Thøgersen-Ntoumani, C. and Cumming, J. and Ntoumanis, N. and Nikitaras, N. 2012. Exercise imagery and its correlates in older adults. Psychology of Sport and Exercise. 13 (1): pp. 19-25. 


\begin{abstract}
Objectives: The purpose of the present study was to test a structural model examining the interrelationships between exercise imagery, self-reported exercise behaviour and well-being in older adults.

Design: Cross-sectional survey.
\end{abstract}

Method: Participants were 499 older Greek adults (50.10\% males) aged between 51 and 84 years $(M$ age $=57.31 ; S D=5.52)$ who completed questionnaires measuring exercise imagery use, exercise behaviour, subjective vitality, and physical self-worth. The relationship between these variables was tested with a structural model based on the applied model of imagery use for exercise (Munroe-Chandler \& Gammage, 2005).

Results: Energy imagery positively predicted exercise behaviour and subjective vitality, and appearance and technique imagery positively predicted physical self-worth.

Conclusions: These results indicate older adults engage in different types of imagery to motivate themselves to exercise and improve their well-being, thus implying that the content of imagery interventions should be specifically tailored to the outcomes older adults wish to realise for interventions to be effective. 


\section{Exercise imagery and its correlates in older adults}

Physical activity plays an important role in successful ageing through the prevention of chronic disease and the promotion of functional capabilities, health, and well-being (Baker, Meisner, Logan, Kungl, \& Weir, 2009; Rowe \& Kahn, 1987). These benefits include reduced risk for cardiovascular disease (Hamer \& Chida, 2008), type 2 diabetes mellitus (Orozco et al., 2008), falling (Gillespie et al., 2003), dementia (Larson et al., 2006), and premature death (Byberg et al., 2009; Sui et al., 2007). The accumulative evidence also indicates that being active in later life lowers the cognitive and metabolic functional declines that normally accompany ageing (DiPietro, Dziura, Yeckel, \& Neufer, 2006; Keysor, 2003), and enhances mental health and quality of life (Penedo \& Dahn, 2005; Rejeski \& Mihalko, 2001).

Despite the physical and psychological importance of being active when older, sedentary behaviour is a major public health concern for adults aged 50 years and over (Prohaska et al., 2006). This age group represents the fastest growing segment of the population and consists of those at greatest risk of chronic disease, disability and health care utilisation (King, Rejeski, \& Buchner, 1998). Many older adults are not participating in sufficient exercise, with only $45.4 \%$ of Greek males and $38.2 \%$ of Greek females aged 60 years and older being regularly physically active (Pitsavos, Panagiotakos, Lentzas, \& Stefanadis, 2005). Similarly, the vast proportion of older adults across a range of European countries are insufficiently physically active to accrue substantial health benefits (Besson et al., 2009). These findings underscore the need to more effectively promote physically active living in this age group and the value of interventions targeting physical activity increases and the maintenance of these behaviours.

Surprisingly, however, research rarely investigates how older adults self-regulate their exercise behaviour, motivation, and well-being. This is of particular importance since most interventions result in only modest changes in physical activity levels (Eakin, Glasgow, \& 
1 Riley, 2000) and many older individuals fail to maintain newly adopted exercise patterns

2 (Ecclestone, Myers, \& Paterson, 1998). Moreover, older adults have identified internal

3 barriers including a lack of motivation as a constraint to their exercise participation (Lees,

4 Clark, Nigg, \& Newman, 2005). Self-regulation, the personal regulation of goal-directed

5 behaviour or performance (Bandura, 1997), is an important contributor to being physically

6 active (Umstattd, Wilcox, Saunders, Watkins, \& Dowda, 2008). Personal strategies (e.g.,

7 goal-setting, planning, self-monitoring and time management) are often incorporated into

8 interventions, but these forms of self-regulation are rarely measured or evaluated (e.g.,

9 Brawley, Rejeski, \& Lutes, 2000; Juneau et al., 1997; Sharpe et al., 1997). The resulting lack

10 of information makes it difficult for organisers of health-promotion programs to identify what

11 are the effective ways of developing self-regulatory processes and, in turn, maximise the

12 likelihood of intervention success (Ayotte, Margrett, \& Hicks-Patrick, 2010).

Imagery is an internal experience that occurs in different sensory modalities and

14 mimics real experience (White \& Hardy, 1998). In his seminal paper, Hall (1995) proposed:

15 1) individuals experience a diverse range of exercise images; 2) exercise images can be

16 classed as serving cognitive or motivational functions; and 3) exercise behaviour would be

17 influenced by experiencing these images, both directly and indirectly by raising expectations

18 of positive outcomes (e.g., health benefits, weight management). Qualitative and quantitative

19 research has supported these predictions and substantiated imagery as a self-regulatory

20 strategy for increasing and/or maintaining exercise behaviour (Gammage, Hall, \& Rodgers,

21 2000; Giacobbi, Hausenblas, Fallon, \& Hall, 2003; Hausenblas, Hall, Rodgers, \& Munroe,

22 1999; Kim \& Giacobbi, 2009; Short, Hall, Engel, \& Nigg, 2004).

A central finding of this research has been that exercisers use three main types of

24 imagery: appearance (motivational function), energy (motivational function), and technique

25 (cognitive function) (Gammage et al., 2000; Hausenblas et al., 1999; Kim \& Giacobbi, 2009). 
1 Appearance imagery involves imaging improvements to one's physical appearance. Energy

2 imagery includes imagery of exercising to distract/motivate as well as feel energized. Finally,

3 technique imagery refers to images of learning and performing exercises correctly. The

4 content and functions of exercisers' imagery forms the core of Munroe-Chandler and

5 Gammage's (2005) applied model of imagery use for exercise, which hypothesises that each

6 type of imagery will impact specific affective, cognitive and behavioural outcomes.

7 Appearance imagery has been positively associated with intention to exercise (Rodgers,

8 Munroe, \& Hall, 2001). By comparison, energy imagery has been positively associated with

9 exercise-induced feeling states of revitalisation, tranquillity, and positive engagement

10 (Cumming \& Stanley, 2009). Further, Cumming (2008) found that technique imagery

11 positively predicted perceptions of task efficacy (e.g., confidence in one's abilities to perform

12 elemental aspects of an exercise task, including pacing oneself and avoiding overexertion;

13 Rodgers \& Sullivan, 2001).

14 Together these results provide support for the applied model of imagery use for

15 exercise and imply different types of imagery can be used to regulate exercise thoughts,

16 feelings, and behaviours (Cumming \& Stanley, 2009). Noteworthy is that the majority of this

17 research has employed samples of mostly young exercisers (Gammage et al., 2000; Giacobbi

18 et al., 2005; Hausenblas et al., 1999). Only a few studies have focused on older adults, but the

19 existing research does suggest exercisers continue to use, and benefit from, the same three

20 types of imagery later in life (Kim \& Giacobbi, 2009; Milne, Burke, Hall, Nederhof, \&

21 Gammage, 2005; Wesch, Milne, Burke, \& Hall, 2006). The present study builds on this

22 burgeoning work by investigating different correlates of exercise imagery use in older adult

23 exercisers. Of particular interest was to examine the relationships between exercise imagery,

24 self-reported exercise behaviour (expressed as metabolic equivalents or METS), and two

25 forms of well-being: physical self-worth and subjective vitality. 
Imagery use is proposed to be a determinant of exercise behaviour (Hall, 1995;

2 Munroe-Chandler \& Gammage, 2005). All three types of exercise imagery play a role in the self-regulation in exercise behaviour for younger adults (Gammage et al., 2000; Giacobbi et al., 2005; Hausenblas et al., 1999), but imagining oneself being fitter or leaner (i.e., appearance imagery) has emerged as the best predictor (Cumming, 2008). Not yet clear is whether this same pattern will be found in older adults. Appearance is a key motive to exercise, also in later life, but older adults reportedly engage in less appearance imagery than younger counterparts (Milne et al., 2005; Pliner, Chaiken, \& Flett, 1990; Smith \& Storandt, 1997). Imagining feelings of being energised and psyched up (i.e., energy imagery) has instead emerged as more important to older adults' exercise behaviour (Wesch et al., 2006). Older adults may also benefit from using imagery by experiencing changes in subjective vitality, a form of eudaimonic well-being that involves feeling alive, invigorated and possessing enthusiasm and energy (Ryan \& Frederick, 1997). The energy available to oneself is an indicator of greater health and physical functioning (Hubley \& Russell, 2009; Ryan \& Deci, 2008), and may also serve as a protective factor against cardiovascular disease (Smart Richman, Kubzansky, Maselko, Ackerson, \& Bauer, 2009). Physical activity is a source of energy and more active older adults report greater subjective vitality than inactive older people (Kerse, Elley, Robinson, \& Arroll, 2005; Stewart et al., 2003). Younger and older adults also use imagery to feel energised and alter their feeling states (Cumming \& Stanley, 2009; Kim \& Giacobbi, 2009). Thus, a greater use of energy imagery may contribute to reports of subjective vitality, both directly and indirectly via changes in exercise behaviour. Older adults also experience concerns of "trying not to look old" and report a strong desire to preserve or improve their appearance (Hardy \& Grogan, 2009). This aspiration is likely reflected by appearance imagery being the most frequently reported imagery type used by older adults (Milne et al., 2005). A negative body image can adversely affect a person's 
1 sense of well-being and quality of life as well as deter them from engaging in physical activity

2 (McLaren, Hardy, \& Kuh, 2003). Exercising, however, can also enhance physical self-worth

3 in older adults by enabling them to feel more competent to carry out their activities and feel

4 better about their appearance (Dionigi \& Cannon, 2009; Mutrie \& Davidson, 1994). Given

5 that these changes match the content of appearance and technique imagery, it is possible that

6 using both types of imagery might improve the valued judgments individuals make about

7 their body, including its abilities and looks (Dionigi \& Cannon, 2009).

9 was to test a structural model examining the relationships between exercise imagery, selfreported exercise behaviour and well-being (subjective vitality and physical self-worth).

11 Based on the extant literature, we hypothesised a direct relationship between the exercise 12 imagery types (energy, technique, and appearance) and self-reported exercise behaviour. A 13 direct relationship, as well as an indirect relationship via exercise behaviour, was also 14 predicted between energy imagery and subjective vitality, technique imagery and physical 15 self-worth, and appearance imagery and physical self-worth.

\section{Method}

\section{Participants}

Participants were 499 community-dwelling Greek adults (50.10\% males) aged between 51 and 84 years $(M$ age $=57.31 ; S D=5.52)$. All participants reported engaging in at least thirty minutes of moderate intensity (physical activity that make people slightly out of

21 breath) or strenuous exercise on a weekly basis. Most of the participants were married 22 (70.90\%). Based on self-reported height and weight measures, Body Mass Index (BMI) was estimated at $26.15(S D=3.63)$.

\section{Measures}


Exercise imagery. The Exercise Imagery Questionnaire (Hausenblas et al., 1999) was

2 adopted as a measure of exercise imagery. Three imagery factors, each containing three

3 items, were examined: energy (e.g., to keep me going during the day, I imagine exercising),

4 appearance (e.g., I imagine a "firmer me" from exercising) and technique (e.g., "when I think

5 about exercising, I imagine doing the required movements"). The participants were provided

6 with a description of imagery and then asked how often they generally use the different

7 images. Each item is measured on a scale ranging from 1 (never/rarely) to 9 (always).

8 Good psychometric properties, including internal reliability coefficients, test-retest reliability

9 and concurrent validity, have been reported for this scale (Hausenblas et al., 1999). Milne et

10 al. (2005) and Wesch et al. (2006) have both reported acceptable levels of internal reliability

11 when the EIQ has been administered to older adults.

12 Exercise behaviour. Godin and Shephard's (1985) leisure-time exercise

13 questionnaire was used as a measure of exercise behaviour during a typical week.

14 Participants were asked to report how often (i.e., frequency) they engaged in mild, moderate

15 and strenuous exercise for 20 minutes or more during a typical week. Examples of mild,

16 moderate and strenuous physical activities were provided to the participants. A total exercise

17 score in metabolic equivalents (METS) was derived by weighting the frequency of mild,

18 moderate and strenuous activities by their respective MET values ( mild $=3$, moderate $=5$,

19 strenuous $=9$ ). Jacobs, Ainsworth, Hartman, and Leon (1993) reported this scale as reliable

20 and as possessing good concurrent validity when compared to various objective activity

21 monitors and fitness indices.

22 Subjective vitality. The Subjective Vitality Scale (Ryan \& Frederick, 1997) was used

23 as a measure of the degree to which participants felt they had energy available to the self.

24 The scale consists of seven items designed to tap feelings of energy and aliveness in general

25 (trait). A seven point anchor response scale was used $(1=$ not at all true $; 7=$ very true $)$. 
1 The scale has demonstrated high internal reliability and evidence of support for its concurrent

2 validity has been reported in previous research (Ryan \& Frederick, 1997).

Physical self-worth. This variable was measured using an adapted version of the

4 physical self-worth subscale (6 items) from the Physical Self-Perception Profile (PSPP; Fox

5 \& Corbin, 1989). Although the scale was originally set out as a forced-choice structured

6 alternative format (with the provision of two alternative statements about what a person think

7 they might be like), we decided to adapt the scale using a format similar to the other variables

8 measured in the present study. This approach has previously been used by other researchers

9 employing the PSPP in research using older adults (e.g., McAuley, Elavsky, Motl, Konopack,

$10 \mathrm{Hu}, \&$ Marquez, 2005). An example item from the physical self-worth sub-scale is "I have a

11 good feeling about myself physically" and in this adapted version, the response scale ranged

12 from 1 (=never) to 4 (= always). Good psychometric properties of the scale, with regard to

13 internal reliability (McAuley et al., 2005; Sonstroem, Harlow, \& Josephs, 1994; Sonstroem,

14 Speliotis, \& Fava, 1992) and test-retest reliability (Fox \& Corbin), have been reported in

15 previous research.

16 Procedures

Prior to study commencement, ethical approval was sought from an ethics review panel at a Greek University. All scales were translated from English to Greek and backwards by a team of three bilingual university professors. When consensus on the item content was reached, the questionnaires were distributed, and supervised, by trained research assistants to

21 older adults in social clubs for the elderly which is a common meeting place for older adults

22 in Greece. All these clubs were based in and around Athens, Greece. With permission of 23 managers of the clubs, the research assistants approached older adults, briefly explained the 24 purpose of the study and asked whether they engaged in regular weekly exercise (i.e., 
1 for at least 20 minutes duration). Once eligible potential participants verbally agreed to take

2 part, they were asked to sign informed consent forms and were reassured that the responses to

3 the questionnaires would remain anonymous and confidential. The research assistants

4 supervised the completion of the questionnaires and were available for questions if needed.

5 Data analysis

Prior to the main analyses, we calculated Cronbach's alpha coefficients and descriptive statistics for all scales used in the study. We also ran a MANOVA analysis to test for possible gender differences in the variables of interest. To test the hypothesised model of interrelationships between the variables in the model, we used structural equation modelling (SEM) analysis using the EQS software (version 6.1; Bentler, 2003) to perform the analysis.

We employed the robust maximum likelihood estimation method because the normalised estimate of Mardia's coefficient was 39.43, indicating departure from multivariate normality.

\section{Descriptive Statistics and Preliminary Analyses}

All scales demonstrated adequate internal reliability (range $\alpha=.72-.84$ ) with one scale displaying marginal reliability (physical self-worth: $\alpha=.67$ ). However, because of the centrality of the construct within the main model we retained this scale. degree and that appearance imagery was the most commonly adopted form of imagery.

With regard to gender differences, a MANOVA test revealed no significant differences in any of the imagery types (Pillai's Trace $=.005 ; F(1,487)=.75 ; p=.53 ;$ partial $\dot{\eta}=.005$ ).

23 Further, independent samples t-tests revealed no significant differences in exercise behaviour $(t(497)=1.37 ; p=.17)$, subjective vitality $(t(496)=.20 ; p=.85)$ or physical self-worth 
$1 \quad(t(497)=.72 ; p=.47)$ between the gender groups. Therefore, we did not consider gender any

2 further.

\section{Testing the Hypothesised Model}

Structural equation modelling was used to model the direct and indirect relationships between the imagery functions, exercise behaviour and the well-being outcomes. Exercise behaviour (METS) was an observed variable in the model. All other constructs in the model were tested as latent factors. The latent constructs of energy, technique and appearance imagery were indexed by their individual sub-scale items. The three imagery factors were inter-correlated. Subjective vitality and physical self-worth were indexed by three indicators (or 'parcels') each. These parcels represent unweighted average scores which are created by pairing up items with the strongest loadings with items with weaker loadings from the same scale (Little, Cunningham, Shahar, \& Widaman, 2002). Parcelling is appropriate to use as a means of increasing the stability of parameter estimates and retaining an acceptable ratio of sample size to estimated parameters in studies which consist of relatively small sample sizes (Bandalos \& Finney, 2001).

The hypothesised model is presented in Figure 1. The solution converged, producing good fit indices (see Hu \& Bentler, 1999): Robust $\chi^{2}(93)=208.10, p<.01$; robust NNFI = .94 , robust $\mathrm{CFI}=.95$, robust $\mathrm{RMSEA}=.05, \mathrm{SRMR}=.05$. However, some of the parameters in the model were not significant. As shown in Figure 1, only energy imagery significantly predicted exercise behaviour, while all three imagery types directly predicted the well-being outcomes. Exercise behaviour significantly predicted subjective vitality and physical selfworth. The indirect effects between energy imagery and subjective vitality $(\beta=.04)$ and between energy imagery and physical self-worth $(\beta=.04)$ were not significant (i.e., $p>.05)$. 
The present study tested the relationships between exercise imagery, self-reported exercise behaviour and well-being (subjective vitality and physical self-worth). Consonant with the applied model of imagery use for exercise (Munroe-Chandler \& Gammage, 2005), we hypothesised a direct relationship between three main types of exercise imagery (energy, technique, and appearance) and self-reported exercise behaviour. A direct relationship, as well as an indirect relationship via exercise behaviour, was also predicted between energy imagery and subjective vitality, between technique imagery and physical self-worth, and between appearance imagery and physical self-worth.

In partial support of our hypotheses, older adults' use of energy imagery was directly related to their self-reported exercise behaviour, but appearance and technique imagery were not significant predictors. Qualitative studies and correlational analyses have previously implicated all three types of exercise imagery in the self-regulation of younger adults' exercise behaviour, but appearance imagery has been reported to be the best predictor (Cumming, 2008; Gammage et al., 2000; Giacobbi et al., 2005; Hausenblas et al., 1999). Indicating the need to consider the participants' age in research of this kind, a different pattern of relationships emerged for older adults in the present study. Rather than images of how one's body looks playing an important role in motivating older adults to exercise, it was instead images of feeling energised. This finding is not altogether surprising because adults aged 50 years and over interviewed by Hardy and Grogan (2009) described how the experience of elevated mood and increased energy encouraged them to adhere to exercise. Wesch et al. (2006) also reported energy imagery to be the strongest predictor of barrier efficacy (i.e., confidence in one's ability to perform a task under challenging conditions or to overcome social, personal, and environmental constraints) and scheduling efficacy (i.e., the confidence in one's ability to schedule or plan strategies for carrying out a specific action). According to Bandura's (1997) social cognitive theory, increases in these 
1 efficacy expectations would lead older adults to have a greater belief in their abilities to

2 successfully carry out behaviours that support their exercise routine, and these beliefs would

3 result in higher physical activity levels. Furthermore, Hall, Rodgers, Wilson, and Norman

4 (2010) recently found energy (and technique) imagery to be more strongly associated with

5 self-determined motivation than appearance imagery in individuals between the ages of 25

6 and 65 years. The authors' interpretation of this finding was formed on the tenets of self-

7 determination theory (Deci \& Ryan, 2000), and led them to propose that better quality of

8 motivation (i.e., more autonomous or self-determined) would result from using energy and

9 technique imagery because these types of imagery are inherent to the actual performance of

10 exercise behaviour. By comparison, appearance imagery reflects an outcome separable from

11 the exercise and is associated with less self-determined reasons for exercising. Thus,

12 converging evidence, including the findings of the present study, point to the importance of

13 encouraging older adults to image themselves energized from exercising as a way to regulate

14 their exercise behaviour and the cognitions that further support this behaviour (e.g., self-

15 efficacy beliefs and motivational regulations).

As expected, a direct relationship between energy imagery and subjective vitality was

found. However, the hypothesised indirect relationship through exercise behaviour was not supported. Stanley and Cumming (2010) previously found that imaging oneself feeling very energized while cycling led to increased revitalization and enjoyment in undergraduate students during, and after, an acute bout of moderate exercise. Furthermore, Cumming and

21 Stanley (2009) reported energy imagery was the best predictor of exercise feeling states in

22 active individuals. The present study indicates that older adults also benefit from using energy imagery by experiencing increased well-being in the form of subjective vitality.

24 Although only in partial support of our predictions, the direct nature of the relationship helps 
1 feelings of vitality (Ryan \& Frederick, 1997). Drawing from Lang's bioinformational theory

2 (1977, 1979), energy imagery likely contains information about the physical and emotional

3 responses (i.e., response propositions) individuals would like to feel in association with a

4 particular situation, such as exercise, or more generally in their everyday lives. Vividly

5 experiencing these responses through imagery would better enable individuals to recognise

6 and/or experience them in real life (Cumming \& Stanley, 2009). For this reason, energy

7 imagery is recommended as a way to improve exercise-related affect and feeling states (e.g.,

8 Cumming \& Stanley, 2009; Munroe-Chandler \& Gammage, 2005; Stanley \& Cumming,

9 2010). In the case of older adults, our findings suggest this recommendation can also be

10 extended to subjective vitality.

Also in line with our hypotheses, appearance and technique imagery were significant

predictors of physical self-worth. Again, however, this relationship was direct rather than indirect through exercise behaviour. Being physically active is considered to improve older adults' physical self-worth by enabling them to feel more satisfied with their appearance and proficient in their exercise abilities (Dionigi \& Cannon, 2009; Mutrie \& Davidson, 1994). In turn, changes in how people value their body can subsequently enhance global self-esteem and thus overall mental health, as well as decrease the internal barriers perceived by older adults to impair their motivation to exercise (Fox, 2000a; Lees et al., 2005). Fox (2000b) suggested that positive perceptions of body image and physical competence might result from simply feeling improvements in one's body as a result of exercising, regardless of whether any improvements actually occur. This is also in line with Hall's (1995) original explanation for why imagery might benefit exercisers; more specifically, to help them raise expectations of positive outcomes. In support of these viewpoints, our findings indicate that older adults who are able to mentally experience desired improvements through imagery report greater physical self-worth. 
We used a composite score to test the relationships, but it is possible that appearance

2 and technique imagery might contribute to different aspects of physical self-worth. For

3 example, imaging one's appearance might lead to greater body satisfaction whereas imaging

4 oneself correctly executing exercises might support perceptions of strength or functional

5 competence (for a discussion on the different components of physical self-worth specific to

6 older adults, see Dionigi \& Cannon, 2009). If this finding was established in future research,

7 it would have important implications for how imagery interventions are designed to improve

8 physical self-worth. For an imagery intervention to be effective, the imaged content should

9 specifically target what individuals wish to change about themselves. An older adult desiring

10 to maintain, or improve, his/her ability to exercise, for example, will more likely benefit from

11 technique imagery than appearance imagery.

Relationships between self-reported exercise behaviour and well-being were found in the present study that was also consistent with previous research. Older adults who were more physically active in their leisure time reported greater subjective vitality and physical self-worth. This not only strengthens advice for using physical activity as a source of energy in older adults, but to also improve how they value their body (Dionigi \& Cannon, 2009; Kerse et al., 2005; Stewart et al., 2003). The greater well-being produced can in turn lead to important changes in the mental and physical health of individuals who are otherwise at high risk for chronic disease and disability (King et al., 1998). Notably, however, a stronger link was found between imagery and well-being than between exercise behaviour and well-being.

21 This finding was unexpected and might be explained by how exercise imagery use was measured. Although the EIQ describes individuals imaging how their appearance, energy, and technique change as a result of exercising (Hausenblas et al., 1999), these images can also apply to everyday situations (e.g., EIQ item \#1 “To keep me going during the day, I imagine exercising"). It is possible that older adults considered different situations when making their 
1 ratings and this led to imagery being a better predictor of well-being than exercise behaviour.

2 This may also explain why our predicted indirect relationships via exercise behaviour were

3 not found. Whilst an older adult's exercise behaviour might not explain this relationship, the

4 applied model of imagery use for exercise points to self-efficacy beliefs as a variable to

5 consider in the future. Munroe-Chandler and Gammage (2005) suggest that different forms of

6 self-efficacy beliefs might at least partially mediate the relationship between imagery and

7 outcomes such as subjective vitality and physical self-worth, and exercise frequency might moderate these effects. Hence, further testing of the model with both younger and older exercisers is warranted with added variables such as self-efficacy.

Another possibility is that other types of imagery not measured by EIQ might be more

11 suitable for exploring the indirect relationships. The EIQ was developed to measure three 12 types of exercise imagery in younger adults and may not fully capture the corresponding content for older participants. Indeed, there are likely more than three types of imagery relevant to older adults. Kim and Giacobbi (2009) reported that older adults also engage in confidence-enhancing images and planning/strategy images related to exercising. The revised version of the Exercise Imagery Inventory (EII-R; Giacobbi, Tuccitto, Buman, \& MunroeChandler, 2010) measures these imagery types (termed exercise self-efficacy and exercise routines imagery respectively) alongside exercise technique, exercise appearance/health, and exercise feelings imagery. Future research should therefore examine the validity and reliability of the EII-R with older adults, as well as explore the suitability of other emerging 21 imagery types (e.g., enjoyment imagery; Stanley \& Cumming, 2010). Further, reports of exercise frequency as measured by the LTEQ only tell us how much older adults are exercising at a particular intensity (mild, moderate, and strenuous), and this information does not capture the quality of their exercise experience. When it comes to well-being effects it is likely that it is the quality, not just the quantity, of the exercise 
1 experience that matters. An individual might exercise often, but if the exercise is done for

2 external, controlling reasons (i.e., less self-determined motivation) it may hamper the usual

3 well-being effects that occur from being physically active (Deci \& Ryan, 2000). In addition

4 to self-report exercise behaviour being a crude measure of frequency and intensity, it might

5 also be affected by memory decay and social desirability biases (e.g., participants reporting

6 how much exercise they think they should be doing rather than how much they actually do).

7 Including more objective and accurate measures of physical activity, such as accelerometers,

8 as well as questionnaires to assess the quality of the exercise experience would be a valuable

9 step for exercise imagery research.

Despite these limitations and the cross-sectional nature of the research, the findings of

11 the present study further advance the literature by providing support for the applied model of 12 imagery use for exercise (Munroe-Chandler \& Gammage, 2005) in older adults. In line with 13 the model's basic premise, each type of imagery was directly associated with conceptually-

14 related outcomes. Extending beyond the outcomes outlined in the model and those measured 15 in previous studies (e.g., Cumming, 2008; Cumming \& Stanley, 2009; Hall et al., 2010;

16 Wesch et al., 2006), our study is the first to demonstrate a relationship between imagery use in 17 older adults and two forms of well-being (subjective vitality and physical self-worth). We 18 also provide evidence to further support the importance of energy imagery in promoting selfregulation of exercise behaviour. Because the pattern of relationships found seems to vary 20 between younger and older adult samples, our results also support the inclusion of age as a 21 moderating variable in the model. Thus, research with older adults should re-examine 22 relationships already established with younger samples between exercise imagery use and 23 outcomes, such as self-determined motivation and feeling states. Further, there are 24 overlooked aspects of the model that still need to be considered, particularly the moderating 25 factors of an individuals' imagery ability, activity type, and physical health status. These 
1 potential moderators seem particularly pertinent to consider with older adult samples. For

2 example, someone with diminished capacities might use imagery differently from a healthy

3 individual. If so, these differences would have implications for how imagery interventions are

4 designed for frail individuals or clinical populations such as those receiving treatment for

5 cancer.

6 In conclusion, relationships were found between types of exercise imagery, exercise

7 behaviour, and well-being that lay the foundation for imagery interventions with older adults.

8 Such interventions would be inexpensive and easy to implement, but few have been

9 conducted to date. A logical, and necessary, step forward for the exercise imagery literature

10 would be test the relationships emerging in the present study with a field-based imagery

11 intervention aimed at improving older adults' exercise behaviour and well-being. In doing so,

12 the ensuing information would enable organisers of health-promotion programmes to more

13 effectively develop self-regulatory processes and, in turn, improve physical activity rates in

14 our ageing population.

15

16 
References

American College of Sports Medicine (1998). Position Stand. The recommended quantity and quality of exercise for developing and maintaining cardiorespiratory and muscular fitness, and flexibility in healthy adults. Medicine \& Science in Sports \& Exercise, 30, 975-991. doi:10.1097/00005768-199806000-00032.

Ayotte, B. J., Margrett, J. A., \& Hicks-Patrick, J. (2010). Physical activity in middle-aged and young-old adults: The roles of self-efficacy, barriers, outcomes expectancies, selfregulatory behaviors and social support. Journal of Health Psychology, 15, 173-185. doi:10.1177/1359105309342283.

Baker, J., Meisner, B. A., Logan, J., Kungl, A., \& Weir, P. (2009). Physical activity and successful aging in Canadian older adults. Journal of Aging and Physical Activity, 17, 235.

Bandalos, D. L., \& Finney, S. J. (2001). Item parcelling issues in structural equation modeling. In G.A. Marcoulides, \& R.E. Schumacker (Eds.), New developments and techniques in structural equation modeling (pp. 269-296). Mahwah, NJ: Lawrence Erlbaum Associates.

Bandura, A. (1997). Self-efficacy: The efficacy of control. New York: W. H. Freeman \& Company.

Bentler, P. M. (2003). EQS 6.1 for Windows [Computer software]. Encino, CA: Multivariate Software.

Besson, H., Ekelund, U., Luan, J., May, A. M., Sharp, S., Travier, N., ...Peeters, P. H. (2009). A cross-sectional analysis of physical activity and obesity indicators in European participants of the EPIC-PANACEA study. International Journal of Obesity, 33, 497506. doi: 10.1038/ijo.2009.25. 
1 Brawley, L. R., Rejeski, W. J., \& Lutes, L. (2005). A group mediated cognitive-behavioral intervention for increasing adherence to physical activity in older adults. Journal of Applied Biobehavioral Research, 5, 47-65. doi:10.1111/j.1751-9861.2000.tb00063.x.

Byberg, L., Melhus, H., Gedeborg, R., Sundström, J., Ahlbom, A., Zethelius, B., ... . Michaëlsson, K. (2009). Total mortality after changes in leisure time physical activity in 50 year old med: 35 year follow-up of population based cohort. British Journal of Sports Medicine, 43, 482-489. doi:10.1136/bmj.b688.

Centers for Disease Control and Prevention. (2003). Public health and aging: Trends in aging-United States and worldwide. Morbidity and Mortality Weekly Report, 52, $101-106$.

Cumming, J. (2008). Investigating the relationship between exercise imagery, leisure time exercise behaviour, and exercise self-efficacy. Journal of Applied Sport Psychology, 20, 184-198. doi:10.1080/10413200701810570.

Cumming, J., \& Stanley, D. M. (2009) Are images of exercising related to feeling states? Journal of Imagery Research in Sport and Physical Activity: Vol. 4 : Iss. 1, Article 5.

Deci, E. L., \& Ryan, R. M. (2000). The "what" and "why" of goal pursuits: Human needs and the self-determination of behavior. Psychological Inquiry, 11, 227-268. doi:10.1207/S15327965PLI1104_01.

Dionigi, R. A. \& Cannon, J. (2009). Older adults' perceived changes in physical self-worth associated with resistance training. Research Quarterly for Exercise and Sport, 80, 269-280.

DiPietro, L., Dziura, J., Yeckel, C. W., \& Neufer, P. D. (2006). Exercise and improved insulin sensitivity in older women: evidence of the enduring benefits of higher intensity training. Journal of Applied Physiology, 100, 142-149. doi:10.1152/japplphysiol.00474.2005. 
1 Eakin, E. G., Glasgow, R. E., \& Riley, K. M. (2000). Review of primary care-based physical activity intervention studies. Journal of Family Practice, 49, 158-168.

Ecclestone, N. A., Myers, A. M., \& Paterson, D. M. (1998). Tracking older participants of twelve physical activity classes over a three-year period. Journal of Aging and Physical Activity, 6, 70-82.

Fox, K. R. (2000a). Self-esteem, self-perceptions and exercise. International Journal of Sport Psychology, 31, 228-240.

Fox, K. R. (2000b). The effects of exercise on self-perceptions and self-esteem In S. J. Biddle, K. R. Fox, \& S. H. Boutcher (Eds.), Physical activity and psychological well being (pp. 88-117). London: Routledge.

Fox, K. R., \& Corbin, C. B. (1989). The Physical Self-perception Profile: Development of preliminary validation. Journal of Sport and Exercise Psychology, 11, 408-430.

Gammage, K., Hall, C., \& Rodgers, W. (2000). More about exercise imagery. The Sport Psychologist, 14, 348-359.

Giacobbi, P. R., Jr., Hausenblas, H. A., Fallon, E. A., \& Hall, C. (2003). Even more about exercise imagery: A grounded theory of exercise imagery. Journal of Applied Sport Psychology, 15, 160-175. doi:10.1080/10413200305391.

Giacobbi, P. R., Jr., Hausenblas, H. A., \& Penfield, R. D. (2005). Further refinements in the measurement of exercise imagery: The exercise imagery inventory. Measurement in Physical Education and Exercise Science, 9, 251-266. doi: 10.1207/s1532784mpee0904_4.

Giacobbi, P. R., Jr., Tuccitto, D. E., Buman, M. P., \& Munroe-Chandler, K. (2010). A measurement and conceptual investigation of exercise imagery establishing construct validity. Research Quarterly for Exercise and Sport, 81, 485-493. 
1 Gillespie, L. D., Gillespie, W. J., Robertson, M. C., Lamb, S. E., Cumming, R. G., \& Rowe, B. H. (2003). Interventions for preventing falls in elderly people. Cochrane Database of Systematic Reviews, 4, CD000340.

Godin, G., \& Shephard, R. J. (1985). A simple method to assess exercise behavior in the community. Canadian Journal of Applied Sport Sciences, 10, 141-146.

Hall, C. (1995). The motivational function of mental imagery for participation in sport and exercise. In J. Annett, B. Cripps, \& H. Steinberg (Eds.), Exercise addiction: Motivation for participation in sport and exercise (pp. 17-23). Leicester: British Psychological Society.

Hall, C. R., Rodgers, W. M., Wilson, P. M., \& Norman, P. (2010). Imagery use and selfdetermined motivation in a community sample of exercisers and non-exercisers. Journal of Applied Social Psychology, 40, 135-152. doi:10.1111/j.15591816.2009.00566.x

Hamer, M. \& Chida, Y. (2008). Active commuting and cardiovascular risk: A meta-analytic review. Preventive Medicine, 46, 9-13. doi:10.1016/j.ypmed.2007.03.006

Hardy, S. \& Grogan, S. (2009). Preventing disability through exercise: Investigating older adults' influences and motivations to engage in physical activity. Journal of Health Psychology, 14, 1036-1046. doi:10.1177/1359105309342298.

Hausenblas, H. A., Hall, C. R., Rodgers, W. M., \& Munroe, K. J. (1999). Exercise imagery: It's nature and measurement. Journal of Applied Sport Psychology, 11, 171180. doi: 10.1080/10413209908404198.

Hu, L., \& Bentler, P. M. (1999). Cutoff criteria for fit indexes in covariance structure analysis: Conventional criteria versus new alternatives. Structural Equation Modeling, $6,1-55$. 
1 Hubley, A. M. \& Russell, L. B. (2009). Prediction of subjective age, desired age, and age satisfaction in older adults: Do some health dimensions contribute more than others? International Journal of Behavioral Development, 33, 12-21. doi:10.1177/0165025408099486.

Jacobs, D. R., Ainsworth, B. E., Hartman, T. J. \& Leon, A. S. (1993). A simultaneous evaluation of ten commonly used physical activity questionnaires. Medicine and Science in Sports and Exercise, 25, 81-91. doi: 10.1249/00005768-199301000-00012.

Juneau, M., Rogers, E, De Santos, V., Yee, M., Evans, A., Bohn, A., DeBusk, R. E (1987). Effectiveness of self-monitored, homebased, moderate intensity exercise training in middle-aged men and women. American Journal of Cardiology, 60, 66-77. doi:10.1016/0002-9149(87)90986-6.

Kerse, N., Elley, C. R., Robinson, E., \& Arroll, B. (2005). Is physical activity counseling effective for older people? A cluster randomized, controlled trial in primary care. Journal of the American Geriatrics Society, 53, 1951-1956. doi:10.1111/j.1532415.2005.00466.x. PMID:16274377.

Keysor, J. J. (2003). Does late-life physical activity or exercise prevent or minimize disablement?: A critical review of the scientific evidence. American Journal of Preventive Medicine, 25, 129-136. doi:10.1111/j.1532-5415.2005.00466.x.

Kim, B. H., \& Giacobbi, P. R. (2009). The use of exercise-related mental imagery by middle-aged adults. Journal of Imagery Research in Sport and Physical Activity: Vol. 4, Iss. 1 , Article 1.

King, A., Rejeski, J., \& Buchner, D. (1998). Physical activity interventions targeting older adults: A critical review and recommendations. American Journal of Preventive Medicine, 15, 316-333. doi:10.1016/S0749-3797(98)00085-3. 
1 Lang, P.J. (1977). Imagery in therapy: An information-processing analysis of fear. Behavior Therapy, 8, 862-886. doi:10.1016/S0005-7894(77)80157-3

Lang, P. J. (1979). A bio-informational theory of emotional imagery. Psychophysiology, 16, 495-512.

Larson, E. B., Wang, L., Bowen, J. D., McCormick, W. C., Teri, L., Crane, P., \& Kukull, W. (2006). Exercise is associated with reduced risk for incident dementia among persons 65 years of age and older. Annals of Internal Medicine, 144, 73-81.

Lees, F. D., Clark, P. G., Nigg, C. R., \& Newman, P. (2005). Barriers to exercise behaviour among older adults: A focus group study. Journal of Aging and Physical Activity, 13, 23-33.

Little, T. D., Cunningham, W. A., Shahar, G., \& Widaman, K. F. (2002). To parcel or not to parcel: Exploring the question, weighing the merits. Structural Equation Modeling, 9, 151-173. doi: 10.1207/S15328007SEM0902_1.

McAuley, E., Elavsky, S., Motl, R. W., Konopack, J. F., Hu, L., \& Marquez, D. X. (2005). Physical activity, self-efficacy, and self-esteem: Longitudinal relationships in older adults. Journals of Gerontology: Psychological Sciences, 60B, P268-P275.

McLaren, L., Hardy, R., \& Kuh, D. (2003). Women's body satisfaction at midlife and lifetime body size: A prospective study. Health Psychology, 22, 370-377. doi:10.1037/0278-6133.22.4.370.

Milne, M. I., Burke, S. M., Hall, C., Nederhof, E., \& Gammage, K. L. (2005). Comparing the imagery use of older and younger exercisers. Imagination, Cognition, and Personality, 25, 59-67. doi:10.2190/AJ75-VWT3-9XHM-UJDW.

Munroe-Chandler, K. J. \& Gammage, K. L. (2005). Now see this: A new vision of exercise imagery. Exercise and Sport Sciences Reviews, 33, 201-205. doi:10.1097/00003677-200510000-00009. 
1 Mutrie, N., \& Davison, R. (1994). Physical self perception in exercising older adults. Journal of Sports Sciences, 12, 203.

Orozco, L. J., Buchleitner, A. M., Gimenez-Perez, G., Roqué i Figuls, M., Richter, B., \& Mauricio, D. (2008). Exercise or exercise and diet for preventing type 2 diabetes mellitus. Cochrane Database of Systematic Reviews, 3, CD003054. doi: 10.1002/14651858.CD003054.pub3.

Penedo, F. J. \& Dahn, J. R. (2005). Exercise and well-being: A review of mental and physical health benefits associated with physical activity. Current Opinion in Psychiatry, 18, 189-193. doi:10.1097/00001504-200503000-00013.

Pitsavos, C., Panagiotakos, D. B., Lentzas, Y., Stefanadis, C. (2005). Epidemiology of leisure-time physical activity in socio-demographic, lifestyle and psychological characteristics of men and women in Greece: the ATTICA study. BMC Public Health, 5, 37-45. doi:10.1186/1471-2458-5-37.

Pliner, P., Chaiken, S., \& Flett, G. (1990). Gender differences in concern with body weight and physical appearance over the life span. Personality and Social Psychology Bulletin, 16, 263-273. doi:10.1177/0146167290162007.

Prohaska, T., Belansky, E., Belza, B., Buchner, D., Marshall, V., McTigue, K...Wilcox, S. (2006). Physical activity, public health, and aging: Critical issues and research priorities. The Journals of Gerontology Series B: Psychological Sciences and Social Sciences, 61, S267-S273.

Rejeski, W. J. \& Mihalko, S. L. (2001). Physical activity and quality of life in older adults. The Journals of Gerontology Series A: Biological Sciences and Medical Sciences, 56, 23-35. 
1 Rodgers, W. M., Munroe, K., \& Hall, C. (2001). Relations among exercise imagery, selfefficacy, exercise behavior, and intentions. Imagination, Cognition, and Personality, 21, 55-65. doi:10.2190/UV5C-0HK0-7NYP-235K.

Rodgers, W. M., \& Sullivan, M. J. (2001). Task, coping, and scheduling self-efficacy in relation to frequency of physical activity. Journal of Applied Social Psychology, 31, 741-753. doi:10.1111/j.1559-1816.2001.tb01411.x.

Rowe, J. W., \& Kahn, R. L. (1987). Human aging: Usual and successful. Science, 237, 143149. doi:10.1126/science.3299702.

Ryan, R. M. \& Deci, E. L. (2008). From ego depletion to vitality: Theory and findings concerning the facilitation of energy available to the self. Social and Personality Psychology Compass, 2, 702-717. doi:10.1111/j.1751-9004.2008.00098.x.

Ryan, R. M., \& Frederick, C. M. (1997). On energy, personality, and health: Subjective vitality as a dynamic reflection of well-being. Journal of Personality, 65, 529-565. doi: 10.1111/j.1467-6494.1997.tb00326.x.

Sharpe, P. A., Jackson, K. L., White C, Vaca, V. L., Hickey, T., Gu, J., \& Otterness, C. (1997). Effects of a one-year physical activity intervention for older adults at congregate nutrition sites. The Gerontologist, 37, 208-215.

Short, S. E., Hall, C. R., Engel, S. R., \& Nigg, C. R. (2004). Exercise imagery and the stages of change. Journal of Mental Imagery, 28, 61-78.

Smart Richman, L., Kubzansky, L. D., Maselko, J., Ackerson, L. K., \& Bauer, M. (2009). The relationship between mental vitality and cardiovascular health. Psychology and Health, 24, 919-932. doi: 10.1080/08870440802108926.

Smith, C., \& Storandt, M. (1997). Physical activity participation in older adults: A comparison of competitors, noncompetitors, and nonexercisers. Journal of Aging and Physical Activity, 5, 98-110. 
1 Sonstroem, R. J., Harlow, L. L., \& Josephs, L. (1994). Exercise and self-esteem: Validity of model expansion and exercise associations. Journal of Sport and Exercise Psychology, $16,29-42$.

Sonstroem, R. J., Speliotis, E. D., \& Fava, J. L. (1992). Perceived physical competence in adults: An examination of the Physical Self-perception Profile. Journal of Sport and Exercise Psychology, 14, 207-221.

Stanley, D. M., \& Cumming, J. (2010). Are we having fun yet? Testing the effects of imagery use on the affective and enjoyment responses to acute moderate exercise. Psychology of Sport and Exercise, 11, 582-590. doi:10.1016/j.psychsport.2010.06.010.

Stewart, K. J., Turner, K. L., Bacher, A. C., DeRegis, J. R., Sung, J., Tayback, M., \& Ouyang, P. (2003). Are fitness, activity, and fatness associated with health-related quality of life and mood in older persons? Journal of Cardiopulmonary Rehabilitation and Prevention, 23, 115-121.

Sui, X., LaMonte, M. J., Laditka, J. N., Hardin, J. W., Chase, N., Hooker, S. P., \& Blair, S. N. (2007). Cardiorespiratory fitness and adiposity as mortality predictors in older adults. The Journal of the American Medical Association, 298, 2507-2516.

Umstattd, M. R., Wilcox, S., Saunders, R., Watkins, K., \& Dowda, M. (2008). Selfregulation and physical activity: The relationship in older adults. American Journal of Health Behavior, 32, 115-124.

US Surgeon General's Report. (1996). Physical activity and health. Washington, DC: United States Department of Health and Human Service.

Wesch, N. N., Milne, M. I., Burke, S. M., \& Hall, C. R. (2006). Self-efficacy and imagery use in older adult exercisers. European Journal of Sport Science, 6, 197-203. doi:10.1080/17461390601012512. 
Older adults' exercise imagery 28

1 White, A. \& Hardy, L. (1998). An in-depth analysis of the uses of imagery by high-level

2 slalom canoeists and artistic gymnasts. The Sport Psychologist, 12, 387-403.

3

4

5 
Table 1.

Descriptive Statistics for all Variables

\begin{tabular}{lcc}
\hline Variable (range) & $M$ & $S D$ \\
\hline 1. Exercise (METS) & 29.30 & 19.79 \\
2. Energy imagery (1-9) & 4.59 & 2.34 \\
3. Appearance imagery (1-9) & 5.39 & 1.95 \\
4. Technique imagery (1-9) & 5.20 & 1.90 \\
5. Subjective vitality (1-7) & 4.69 & 1.20 \\
6. Physical self-worth (1-4) & 2.66 & .57 \\
\hline
\end{tabular}

Note. $*=p<.05 ; * *=p<.01$ 
Older adults' exercise imagery 30

Figure 1.

Modelling the hypothesized relationships between exercise imagery, exercise behaviour (METS) and well-being outcomes 
Older adults' exercise imagery 31

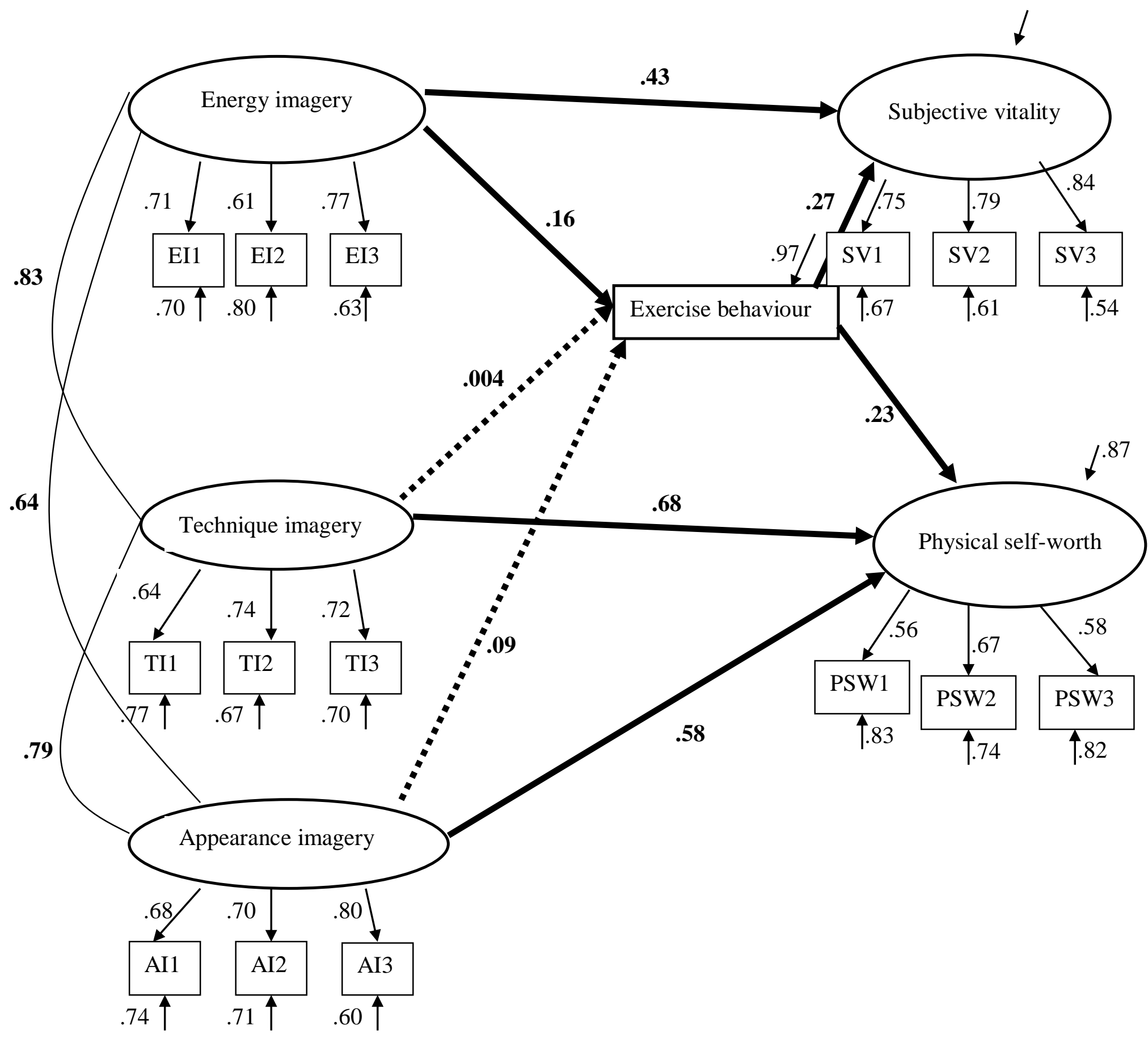

Note. The two dotted lines indicate non-significant (at $p>.05)$ parameters. Ovals indicate latent factors and the rectangle represent an observed variable. 